\title{
Understanding customer relationship management (CRM) adoption in an Arab Middle Eastern context
}

Article

Accepted Version

Jaber, F. N. and Simkin, L. (2017) Understanding customer relationship management (CRM) adoption in an Arab Middle Eastern context. Behaviour and Information Technology, 36 (10). pp. 1020-1036. ISSN 1362-3001 doi:

https://doi.org/10.1080/0144929X.2017.1332098 Available at https://centaur.reading.ac.uk/70582/

It is advisable to refer to the publisher's version if you intend to cite from the work. See Guidance on citing.

To link to this article DOI: http://dx.doi.org/10.1080/0144929X.2017.1332098

Publisher: Taylor and Francis

All outputs in CentAUR are protected by Intellectual Property Rights law, including copyright law. Copyright and IPR is retained by the creators or other copyright holders. Terms and conditions for use of this material are defined in the End User Agreement.

www.reading.ac.uk/centaur 
Central Archive at the University of Reading

Reading's research outputs online 


\section{Understanding Customer Relationship Management (CRM) Adoption in an Arab Middle Eastern Context}

Faten N. Jaber ${ }^{\mathrm{a}^{*}}$ and Lyndon Simkin ${ }^{\mathrm{b}}$

${ }^{a}$ Henley Business School, University of Reading, UK; ${ }^{b}$ Centre for Business in Society, Coventry University, UK

*faten.jaber@henley.ac.uk 


\title{
Understanding customer relationship management (CRM) adoption in an Arab Middle Eastern context
}

\author{
While the development of CRM started in the developed west, it has rapidly spread to \\ developing countries. However, the way organisations adopt CRM in developing \\ countries, and more specifically in the Arab world might be different and the context \\ certainly differs. There is a shortage of rigorous studies that examine drivers of CRM \\ adoption in this context. In this study we examine the antecedents of CRM adoption in the \\ Jordanian service sector. The conceptual framework of this research is tested using a cross- \\ sectional survey of more than 322 practitioners. Using structural equation modelling \\ analysis, results specify six underlying factors that explain CRM adoption: segmentation \\ analysis, clear direction and objectives, performance measurement, rewarding usage, \\ managing project changes, and knowledge management. Each area has implications for \\ improving practices and maximising the benefits of adopting the process or management \\ practice of CRM. This paper identifies key practices to provide useful guidelines for \\ organisations in the Arab world making plans to adopt CRM, with broader implications for \\ the adoption of many systems and projects there and for CRM deployment in \\ developed regions.
}

Adoption process; CRM; innovation diffusion theory; knowledge management; employee perception; marketing operations

\section{Introduction}

The increasing pace of technology has had an evident impact on facets of relationship marketing and approaches for engaging with customers. As a result, we are witnessing a rapid global growth in the number of organisations integrating customer relationship management (CRM) initiatives into their marketing strategies and working processes (Gartner, "The Gartner CRM Vendor Guide, 2016”). In 2015, the CRM global market totalled up to \$26.3 billion. Companies from North America, Europe, Asia/Pacific and Middle East and North Africa (MENA) regions achieved double digit growth in the CRM market (Gartner, "Market Share Analysis: Customer 
Relationship Management Software, Worldwide, 2015"). This proves that CRM is a global concept (Ramaseshan et al., 2006). Nevertheless, most studies of CRM have either focused on Asia/Pacific markets (e.g. Lin et al. 2010; Wang and Feng 2012) or developed markets, such as North America (e.g. Krasnikov et al. 2009; Reimann et al. 2010) and Europe (e.g. Payne and Frow 2005; Rahimi et al. 2017). Findings from these studies are not easily comparable or applicable to companies in the Arab world, as different countries and regions represent varying practices and challenges to CRM (Ramaseshan et al. 2006). Hence, more research is needed to study the usage and implementation of CRM in developing markets, which are becoming increasingly important in their own right (Kumar et al. 2011). This study aims to determine the drivers or antecedents of CRM adoption in Jordan, an Arab developing country and to expand the understanding of CRM adoption and implementation per se.

For many organisations, CRM has yet to deliver on its promises (Kim et al. 2012). The high failure rate of CRM projects suggests that researchers ought to provide business practitioners with better tools, which are useful for managing these projects (Forrester, "Map the way to your CRM business outcomes"). Industry studies have consistently emphasised that a lack of commitment to the core principles of CRM may explain why many organisations are disappointed by CRM implementation (Forrester, "Map the way to your CRM business outcomes"; Zahay et al. 2014). While there is a substantial body of literature concerning CRM and its adoption, research around this phenomenon is widely scattered and fragmented across different disciplines and perspectives (Gebert et al. 2003; Reinartz, Krafft, and Hoyer 2004; Boulding et al. 2005; Horn, Feinberg, and Salvendy 2005; Rahimi et al., 2017). Although this makes a core approach difficult to map, such diversity indicates that adoption issues encompass a wide variety of technical, business and social factors, as found in the 
prevailing literature. Taken as a whole, the complexity of CRM reflects the need for a fundamental interdisciplinary approach to solve many of its problems. Hence, an understanding of potential factors influencing CRM adoption is crucial, exploring issues at the corporate/managerial, marketing and IT levels.

Management scholars propose that an organisation's strategic plan (Osarenkhoe and Bennani 2007), internal marketing (Rigby, Reichheld, and Schefter 2002), and project management (Wilson, Daniel, and McDonald 2002) all have strong influences on the success of CRM. Marketing scholars view CRM as a concept that adds value to the customer and they are primarily concerned with the essentials of customer-centric and relationship marketing (Grönroos 2000; Tukel and Dixit 2013). They view CRM as an effective business strategy, given that customer-centric orientation places customer knowledge, interaction, acquisition, value, satisfaction, and retention at the centre of the value creation process. On the other hand, IT scholars focus on software applications (Wu and Wu 2005; Navimipour and Soltani 2016) and knowledge management (KM) (Romano and Fjermerstad 2003; Soltani and Navimipour2016; Tseng 2016) aspects of CRM. A closer look at management, marketing, and IT domains, and their corresponding perspectives, will be taken in the theoretical background section.

\section{Jordan as a research context}

Jordan is located in the heart of the Middle East. The local technological capacity there has improved with the aspiration of transforming it into a leading country in the area of information and communications technologies (ICT) in the Middle East. The rapid growth of ICT usage and development has made the Middle East region competitive in the world. A Gartner (2015) report revealed that CRM spending in the Middle East has achieved a high growth rate at 10.7 percent. However, the adoption of CRM by organisations there is still lagging behind compared to 
organisations in developed countries, such as North America.

The services sector in Jordan is well advanced and generally adheres to the highest standards by benchmarking international best practices (European Union, "Countries and Regions: Jordan"). While the value of the service sector accounts for $78.4 \%$ of the UK economy, it is also significant in Jordan and accounts for $66.4 \%$ of its economy (The World Bank, "Services, etc., value added (\% of GDP)"). In light of the recent development of information technology there, CRM has become one of the main strategies considered by its businesses for the enhancement of customer relationships. Hence, conducting this study in the Jordanian service sector is valuable as it will help in understanding the drivers of CRM adoption in the Middle East/Arab world region.

\section{Theoretical Background}

\subsection{The CRM adoption process}

Too often organisations hand over CRM implementation to the IT department, which focuses on installing CRM tools and solutions (Pedron and Caldeira 2011), rather than appreciating the strategic benefits of managing customer relationships for revenue retention and growth. This leads

to the creation of an operational tool for the company, but the usability and effectiveness of such a tool is limited (Forrester, "Map the way to your CRM business outcomes"). Researchers from different disciplines have suggested various frameworks to help organisations implement CRM successfully. In their critical comparison between the literatures of marketing and the information systems (IS) disciplines, Maklan, Peppard, and Klaus (2015) reveal that IS scholars have developed a better understanding and conceptualisation of the process of CRM investment and its impact upon business performance than their marketing colleagues. They further explain that this 
is particularly true because IS scholars consider human and organisational perspectives for the CRM system, and thereby promote a greater role for CRM in strategic decision-making. While this view is central in the IS literature, it is mostly absent in the marketing literature aside from the well-established call for top management support.

In the information technology area, the general problem of innovation adoption is discussed using different theoretical foundations. Most studies have focused on individual acceptance, which refers to the idea that employees must use the CRM system to achieve marketing goals which are often correlated with other constructs (e.g. Hsu and Chiu 2004). The technology acceptance model (TAM) developed by Davis (1989) is particularly useful for explaining information system usage behaviour. However, critics point out that TAM is rather over-simplified in an organisational adoption context ( $\mathrm{Wu}$ and $\mathrm{Wu} 2005)$. Their main concern is that TAM ignores the essentially social process of CRM implementation; the adoption of CRM comprises employees' acceptance, while it is also correlated to the widespread implementation of CRM strategy/technology. In other words, TAM is only useful in an individual acceptance context.

On the other hand, the work of Rogers (1983) on innovation diffusion theory (IDT) suggests that organisational adoption of information systems unfolds as a series of stages, starting with developing knowledge about the new information system/innovation through to persuasion, decision, implementation, and confirmation. In a rare attempt, Ko et al. (2008) adapted the work of Rogers (1983) on IDT to understand the adoption of CRM. They focused on two main stages of IDT: persuasion (which they referred to as perception) and implementation. Perception relates to cognitive beliefs underpinning employees' attitudes towards CRM. Developing a positive perception about CRM benefits would lead to an adoption decision 
concerning CRM implementation across an organisation. In turn, this stage would depend on organisational deployment of specific CRM technologies/strategies. These two stages might be useful for reflecting on CRM adoption from two different angles: that of individual/employee acceptance and that of organisational adoption. This multi-stage approach holds that employees' perception of CRM offerings mediates the influence of CRM adoption factors on CRM implementation within an organisation.

Despite the efforts of Ko et al. (2008), their study is limited to the effects of organisational characteristics (i.e. organisational size, CEO age and education, product category, etc.) on CRM adoption, overlooking some other important marketing and technological factors, such as customer-centric orientation and knowledge management. Building on the two stages of the CRM adoption process proposed by Ko et al. (2008), this paper attempts to examine the relationship between a wide variety of factors and CRM adoption. Although the terms 'adoption' and 'implementation' are similar and used inter-changeably in the literature, the term 'implementation' in this study means a widespread usage of CRM within an organisation, while 'adoption' refers to sequential phases of the innovation diffusion process, which mainly includes employees' acceptance of CRM and the implementation of CRM within the organisation. Businesses need to place emphasis on people issues as a priority, before investing in expensive CRM technologies (Shum, Bove, and Auh 2008). Boulding et al. (2005), in their review of the CRM literature, emphasised the important role of employees, but noted that little is known about how employees relate to CRM activities. Vella and Caruana (2012) indicate that aligning employees' needs with CRM strategies is vital for CRM implementation. That is, while CRM must be incorporated into the work processes of the organisation, it can only succeed if the system is accepted by individuals as a way of thinking about customers as being valuable 
(Trainor et al. 2011). Similarly, the theory of reasoned action, also known as attitude theory (e.g. Fishbein and Ajzen 1975), suggests that beliefs mediate the influence of external factors on behavioural decisions. In the context of organisational adoption of CRM, it has been noted that the beliefs or perceptions of individuals in organisations, in relation to CRM benefits, tend to mediate the impact of external factors on the implementation of CRM (Plakoyiannaki 2005; Navimipour and Soltani, 2016). Building on these suggestions from the literature, this study proposes that management teams must plan ahead and prepare for CRM implementation by first managing employees' perceptions of CRM. Moreover, positive perception of CRM gives both purpose and direction towards its successful implementation.

\section{$H_{1}$ : Employee perceptions of CRM benefits mediate the effect of adoption factors on an organisation's implementation of CRM.}

\subsection{CRM adoption factors}

In their attempt to develop a convergence of different aspects, Payne and Frow (2005), influential researchers from the Anglo-Australian school of relationship marketing, used a continuum to define CRM from three different levels/approaches. At a low level of detail, CRM is narrowly and tactically defined, while at a high level of abstraction, CRM is broadly and strategically defined. The first perspective applies a narrow and tactical outlook where CRM is accomplished through a defined technology initiative project. This tactical perspective takes technology as its driving force, and describes CRM as using data to drive marketing activities (Kutner and Cripps 1997). It also looks upon CRM as a marketing promotional activity linked to marketing databases focusing on efficient selling of products and services (Winer 2001). Researchers from the IT discipline have contributed to this tactical approach by providing 
guidelines on how to make efficient use of the technology (Romano and Fjermestad 2003; Wu and $\mathrm{Wu} 2005)$.

On the other hand, strategic approaches apply a holistic view to CRM, and embed it in a business's wider strategy. This strategic orientation of CRM links to customer-centric strategy that aims at developing one-to-one relationships with customers. Researchers from the business discipline have contributed to this perspective by outlining that CRM implementation relies on the alignment of CRM with business strategy, organisation and process, monitoring and control, and culture (Parvatiyar and Sheth 2001; Ocker and Mudambi 2003; Foss et al. 2008). The implementation of strategic CRM approaches is conducted through a long-term perspective, which predicts changes not only to organisational structure but also to organisational culture. Determinants of CRM success are well summarised in the framework suggested by Payne and Frow in their subsequent study in 2006. The model has two main components: four key CRM implementation elements (CRM readiness assessment, CRM change management, CRM project management, and employee engagement) and five core CRM processes (strategy development, value creation, multi-channel integration, information management and performance assessment). Despite the novel contribution of Payne and Frow's framework, the qualitative approach of their study does not seek to specify the particular elements that fall under the nine abstract concepts in this framework. More detailed research is needed to identify the intrinsic aspects underlying these concepts. While intuitively appealing, Payne and Frow's framework has not been empirically tested, although some support of its elements are inferred from different studies across the marketing, management, and IT literatures (Kim and Kim 2009; Garrido-Moreno and PadillaMelendez 2011; Kim et al. 2012; Rahimi and Gunlu 2016). Hence, the perspective of this paper is based upon valid prior knowledge regarding adoption factors across these disciplines. Table 1 
represents an attempt to incorporate the vast and expansive scope of factors leading to CRM adoption from these three disciplines. 
Table 1. Three perspectives on CRM adoption factors

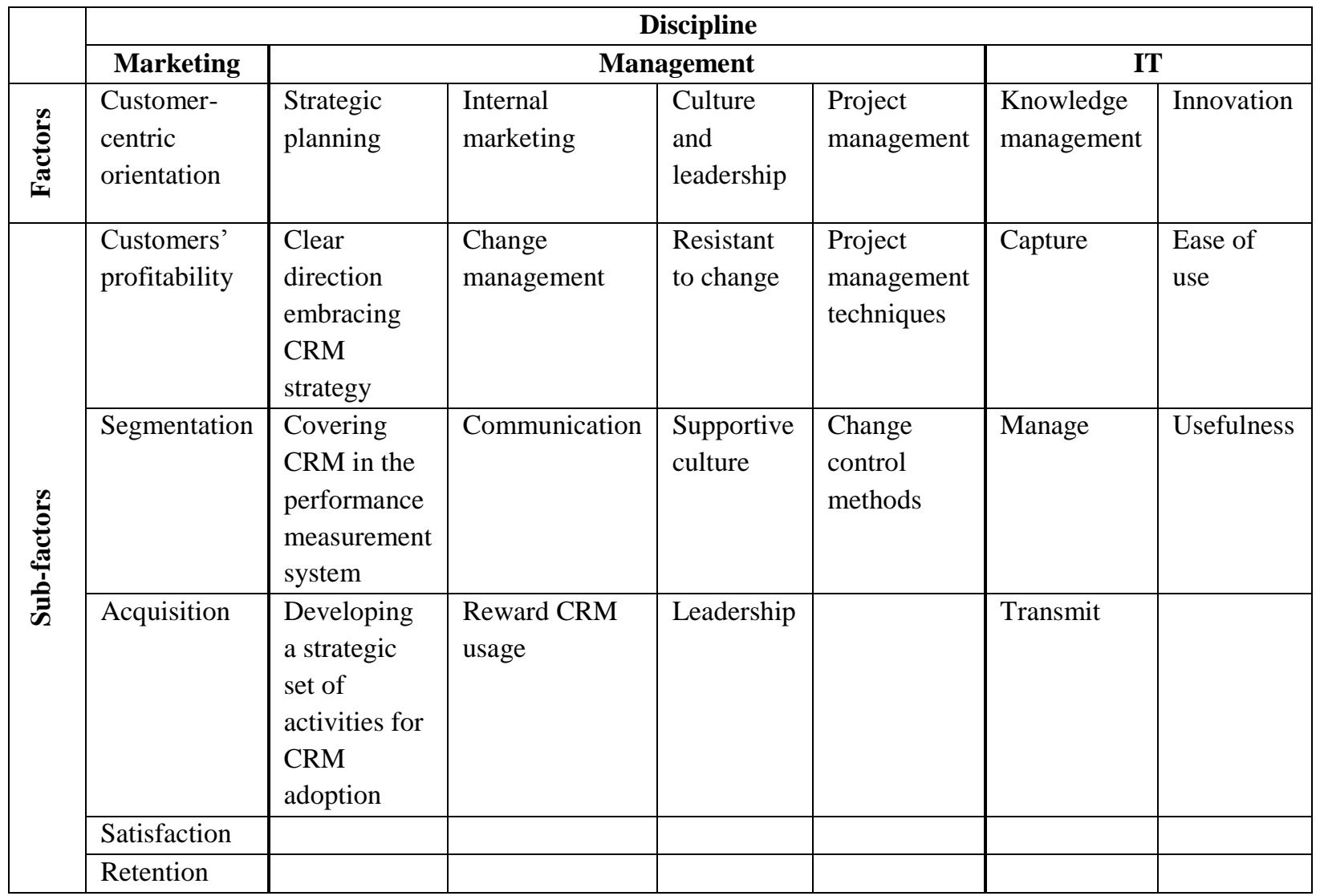

In-depth interviews with nine firms were conducted to ground the research and confirm factors of importance in the Arab world, from a practical perspective. By relying on a combination of theoretical insights and field research, key factors were selected to focus on emphasis on customer segmentation and satisfaction, clear direction, performance measurement, rewarding CRM usage, managing changes in CRM projects, and managing and sharing customer knowledge. The selection of nominated factors will be discussed in the following sub-sections.

\subsubsection{The marketing discipline}

Marketing scholars often criticise the practice of adopting CRM in organisations for not going far enough to reform an underlying culture that is customer focused. They argue that for CRM to 
reap its benefits, businesses need to consider it as a way of thinking that focuses on customers (Kim et al. 2012). Hence, CRM should be approached as a way to make customer segmentation, acquisition, profitability analysis, satisfaction and retention much easier for businesses (Tukel and Dixit 2013). Given the relevant importance of these elements to businesses, they often arise in most CRM studies from marketing domain (e.g. Trainor et al. 2011; Meadows and Dibb 2012). Thus, it is logical that customer-centric orientation elements are worthy of serious consideration (Padilla-Meléndez and Garrido-Moreno 2014).

A juxtaposition of the literature on segmentation and CRM has resulted in the identification of a number of links between these two notions. According to Reimer, Rutz, and Pauwels (2014), the prevailing literature of CRM mostly focuses on predicting customer purchases and/or analysing customer profitability. Bailey et al. (2009) suggest that organisations should optimise a traditional segmentation process using the rich data on individual customers offered from CRM. Indeed, one reason segmentation is so central is because it stresses the importance of gaining customer insights in order to plan accordingly for effective resource allocation (Clark and Baker 2004). Rigby et al. suggest that the adoption of CRM without 'good old fashioned segmentation' $(2002,2)$ is doomed to failure. This is mainly because the effective use of traditional segmentation analysis plays a critical role in helping businesses relate to CRM values. Therefore, an effective CRM scheme may be derived by means of convergence between segmentation techniques and the current capabilities of CRM (Roland and Verhoef 2005; Bailey et al. 2009). Hence, it can be concluded that segmentation links CRM to a customer-centric orientation strategy. This orientation should lead to focusing organisational structure and culture around customers. Taking responsibility for segmenting customers as a key trait of customer-centric 
orientation - which may include the activities of building and updating a customer database - is therefore essential in meeting the challenges of adopting CRM (Blattberg et al. 2009).

Meadows and Dibb (2012) suggest that the differences between CRM perspectives reflect what they describe as a journey from segmentation to CRM. With the weak institutional systems and the underdeveloped governance structure in the Arab world, it is not surprising that businesses in this region are struggling to progress in this journey to develop a true customercentric orientation climate in their organisations (Ramaseshan et al. 2006). Based on prior argument, it can be assumed that organisations in the Arab world are in the early stages of their journey with CRM, and hence are beginning that journey by relating existing segmentation analyses to CRM benefits. To embark on their journey, such organisations need to increase their understanding of CRM concepts and to promote the promising benefits of CRM more effectively for their members.

$\mathrm{H}_{2}$ : Organisation's emphasis on segmentation analysis will have a positive effect on employee perceptions of CRM.

According to Kotler, Keller, Brady, Goodman and Hansen (2016), customer satisfaction is the extent to which a product's perceived performance matches or surpasses the customer's expectations. It is at the core of the marketing concept which has been the guiding force for leading businesses. Businesses' interest in customer satisfaction has rapidly increased, as the strong links between customer satisfaction, loyalty, and profitability have become clearer. Therefore, most companies are using customer satisfaction as the best indicator of evaluating business and marketing performance (Tuli and Bharadwaj 2009). With an increasingly high intensity of competition, facilitated by a dramatically wider variety of alternatives available to 
customers on the internet, businesses are pressured to acknowledge the changes in the power of customer choice, and to shift from mass marketing to customer-centric and relationship marketing (Chen and Popovich 2003). CRM helps businesses to identify customers' behaviour patterns and future needs, to determine their satisfaction level, and to support customer segmentation (Chen and Popovich 2003; XU and Walton 2005; Maklan and Knox 2009). The goal of CRM is to manage the interaction with customers and maintain long-term relationship marketing elements such as commitment, trust and satisfaction (Park and Kim 2003). Researchers also suggest that the underlying culture and systems of an organisation designed round customer satisfaction is likely to influence CRM adoption (Swift 2000).

\section{$H_{3}$ : Organisation's emphasis on customer satisfaction will have a positive effect on employee perceptions of CRM.}

\subsubsection{The management discipline}

From a management perspective, businesses are concerned with organisational issues related to CRM business strategy development and implementation, and the role of people and organisations in managing CRM adoption. The review of the literature suggests that these organisational issues also include clear direction and objectives, performance measurement mechanisms, internal marketing and rewards, plus project management.

CRM involves substantial restructuring of organisational elements and processes, often planning strategic organisational change, with an aim to maximise the value of relationships with customers (Newby, Nguyen, and Waring 2014). Strategic planning processes need to be adapted for the new customer-centric philosophy (Gurau, Ranchhod, and Hackney 2003). More specifically, strategic planning is needed to ensure that organisations have clear objectives, goals, 
and an implementation plan in order to keep the organisation engaged, focused, and effective during the adoption process (Osarenkhoe and Bennani 2007). Steel, Dubelaar, and Ewing (2013) argue that a strong strategy is a prerequisite to focusing CRM solutions on business objectives which will yield the highest return on investment. Thus, it is suggested that clear CRM direction and objectives are basic criteria for employees to perceive/evaluate CRM to be potentially beneficial for their organisation, since these criteria provide accountability for strategies geared toward customer focus. Consequently, if management forms sufficiently clear objectives of CRM, then the employees will adopt the same attitude in following CRM initiatives.

$H_{4}$ : Having clear direction and objectives that embrace CRM strategy will have a positive effect on employee perceptions of CRM benefits.

Several studies suggest that organisations focusing on the importance of performance measurement are more likely to perceive the benefits of implemented innovation (Morgan 2004; Sawang et al. 2006; Zahay et al. 2014). Similarly, Payne and Frow (2006) suggest that in order to achieve CRM objectives, organisations need to focus on measuring whether the strategic aims of CRM have been delivered to an acceptable standard. Nevertheless, developing a performance measurement system that is flexible with employee attitudes is a real challenge for organisations adopting CRM (Morgan 2004). This is reaffirmed by the findings of Kim and Kim (2009), indicating that the performance measurement systems used by organisations are generally underdeveloped in measuring CRM performance and aiding its adoption. Given that the adoption of CRM is associated with long-term projects (Kim and Kim, 2009), the question arises concerning whether these projects are equally able to serve CRM objectives in each of the project's stages. This suggests that an organisation needs first to define an appropriate CRM strategy and to 
outline priorities that fit with its corporate business strategy, then to build clear CRM measures to assess its strategy, and finally to cascade these across the organisation. This interrelated process would better lead to an in-depth understanding of CRM effectiveness and of what should be done to achieve outcomes.

\section{H5: Appropriate CRM performance measurement mechanisms in an organisation will have a positive effect on employee perceptions of CRM benefits.}

The leading exponents of CRM have urged caution on organisational and communication issues that may potentially hinder the effective adoption of CRM (Cascio, Mariadoss, and Mouri 2010). Grönroos (2000), a vigorous leader of the Nordic school of relationship marketing, stresses that effective relationship marketing is only attained by organisational practice of internal marketing, which generally involves creating an appropriate organisational climate. Such an understanding emphasises that internal marketing can be extended to creating an appropriate organisational climate for adopting CRM with cross-functional working quality (Ballantyne 2003; Payne and Frow 2006). As such, there is a strong need for businesses to motivate and influence their employees to adapt to their internal process as needed for effective CRM implementation (Rigby, Reichheld, and Schefter 2002; Shum, Bove, and Auh 2008).

The literature shows that CRM implementation is aided by an organisation's use of a reward system to boost employee motivation and reduce resistance to change (Reintarz et al. 2004; Kim and Kim 2009). In particular, organisations offering incentives strongly oriented towards retaining, rather than capturing customers, are seen to be engaged in developing a very customer-centric culture (Day 1999). According to Plakoyiannaki (2005), reward systems should acknowledge and reward the contribution of employees, since it is they who can best influence 
company outcomes in the workplace. Such rewards are likely to result in an enhanced sense of impact and in a reinforced perception of personal competencies. This means that successful CRM implementation needs an organisational structure and a reward system that specifically serve CRM initiatives rather than undermining them. For example, an organisation needs to have a way of measuring and rewarding customer satisfaction, which can be attained directly through surveys, or indirectly through monitoring proxy measures (Day 1999).

\section{H6: Rewarding CRM usage will have a positive effect on employee perceptions of CRM.}

The vast combination of technical elements and the myriad of organisational and employee issues make CRM projects highly complex; hence, project managers may face difficulties in monitoring and adjusting CRM project plans (Wilson, Daniel, and McDonald 2002). Therefore, project planning could be seen as an essential step in implementing CRM projects, since without a project plan, CRM implementation risks experiencing issues such as inadequate resources, unclear scope, poor scheduling and the loss of quality control (Man et al. 2006). Organisations need to identify CRM objectives and recognise their priorities; such objectives should be derived from the corporate objectives and sustain the overall business strategy. Accordingly, a project manager is advised to clarify the goals of CRM projects and the means for measuring their performance against these goals (Somers and Nelson 2001). Clarification and implementation of these goals can be seen to constitute the critical success factors of the project, to be used as benchmarks for evaluating CRM initiatives. On the other hand, it must be recognised that CRM projects are large-scale projects requiring attention beyond their completion, as the true benefits of CRM are only recognisable once the initial projects have been completed (Meyer 2005). 
According to Payne and Frow (2006), CRM credibility runs the risk of being completely or significantly damaged if a CRM project plan slips badly; for instance, coming to completion after originally agreed deadlines or coming in over the original agreed budget. Thus realistic advance scoping of a project in terms of management capacity is essential so that the planning of CRM objectives is clearly known to all stakeholders; in this way the risk of over-running budgets and timescales is minimised. Hence, having appropriate project schedules, plans, and a clear strategy for CRM implementation is a necessity for CRM projects (Somers and Nelson 2001; Ranjan et al. 2008). In this, a project manager should be cautious of too broad or ambitious a project scope, as sometimes initial commitments overlap or lack specifics (Somers and Nelson 2001). The use of good project management practices effectively underpins customer management capabilities (Payne 2006). This capability refers to the project management team's ability to adjust project plans on an ad-hoc basis. Wilson, Daniel, and McDonald (2002) emphasise that project management teams need to monitor and control CRM implementation, in order to ensure flexibility and adjustment to unexpected changes. Additionally, Mckay (2009) highlights that an agreement before the start of the project as to the distribution of milestones could facilitate the monitoring and control process.

Researchers suggest that CRM would be best optimised by cross-functional engagement and development across departments on the part of marketing and technical personnel (Gefen and Ridings 2002; Enz and Lambert 2012; Tukel and Dixit 2013). This is because CRM implementation may be challenged by varying perspectives and attitudes of employees from different business units within an organisation. In order to co-ordinate these, collaboration of cross-functional teams from different business units (IT, Marketing, and HRM) and management hierarchies will help in aligning the different perspectives of CRM (Ryals and Knox 2001). 
H7: Managing changes in CRM projects will have a positive effect on employee perceptions of CRM.

\subsubsection{The IT discipline}

Researchers from the IT discipline mainly discuss how organisational adoption of CRM requires knowledge management (KM) development in order to provide people with useful linkage between innovation and its benefits (Carneiro 2000). In particular, knowledge about profitable customers is vital for CRM, as it aids the development of a 'learning relationship' between the organisation and customers (Sin, Tse, and Yim 2005). Information on customers can be captured indirectly through business intelligence tools, such as data mining, or directly through employees. However, it is a daunting challenge to persuade employees to record and share information they have cultivated on customers (Gibbert, Leibold, and Probst 2002), which is why organisations need to consider plans for incentives which would encourage knowledge generation and sharing.

Customer interactions with organisations are not limited to sales and marketing departments but extend to a variety of different people and departments at different levels. Dous et al. (2005) explained that some organisations may neglect KM in CRM due to the difficulty of realising immediate or short-term benefits of relative projects. Alavi and Leidner (2001) considered $\mathrm{KM}$ as the process of capturing, managing, and transmitting knowledge through the organisation and across organisational boundaries (Bose and Sugumaran 2003; Lee-Kelley, Gilbert, and Mannicom 2003). According to Croteau and Li (2003), storing and updating relevant knowledge for CRM initiatives calls for the deployment of KM. Although the literature varies between knowledge about, for, and from customers (Gebert et al. 2003), creating knowledge about customers is generally described as the first step to equip KM capabilities. 
Collecting knowledge about customers is one of the oldest forms of KM that enables the application of CRM in organisations (Reichheld and Schefter 2000).

Since acquiring customer information, and subsequently customer knowledge, is a means to attaining CRM objectives, CRM is strongly related to KM (Massey, Montoya, and Holcom 2001). It is also notable that the majority of organisations appear to fail in implementing CRM projects because of the improperly conducted KM, which leads to a narrow and incomplete view of customers (Romano and Fjermerstad 2003; Garrido-Moreno and Padilla-Melendez, 2014). Hence, from the potential synergy between CRM and KM, a theoretical model has emerged of customer knowledge management (Gebert et al. 2003; Khodakarami and Chan 2014). This model indicates that CRM adoption entails an organisation refining and realigning KM methods in order to obtain a value-added knowledge from and about customers, usefully revealing not only customer purchasing behaviour and trends but preferences and attitudes. Such realignment involves a change in the organisational vision and leads to enhanced learning and innovation within an organisation (Khodakarami and Chan 2014).

$H_{8}$ : Organisational capability to manage customer knowledge will have a positive effect on employee perceptions of CRM.

H9: Organisational capability to share customer knowledge will have a positive effect on employee perceptions of CRM.

\section{Conceptual framework}

Based on an extensive review of the literature, a conceptual framework has been developed for this study to incorporate areas of specific interest, as shown in Figure 1. 
Figure 1. Proposed conceptual framework

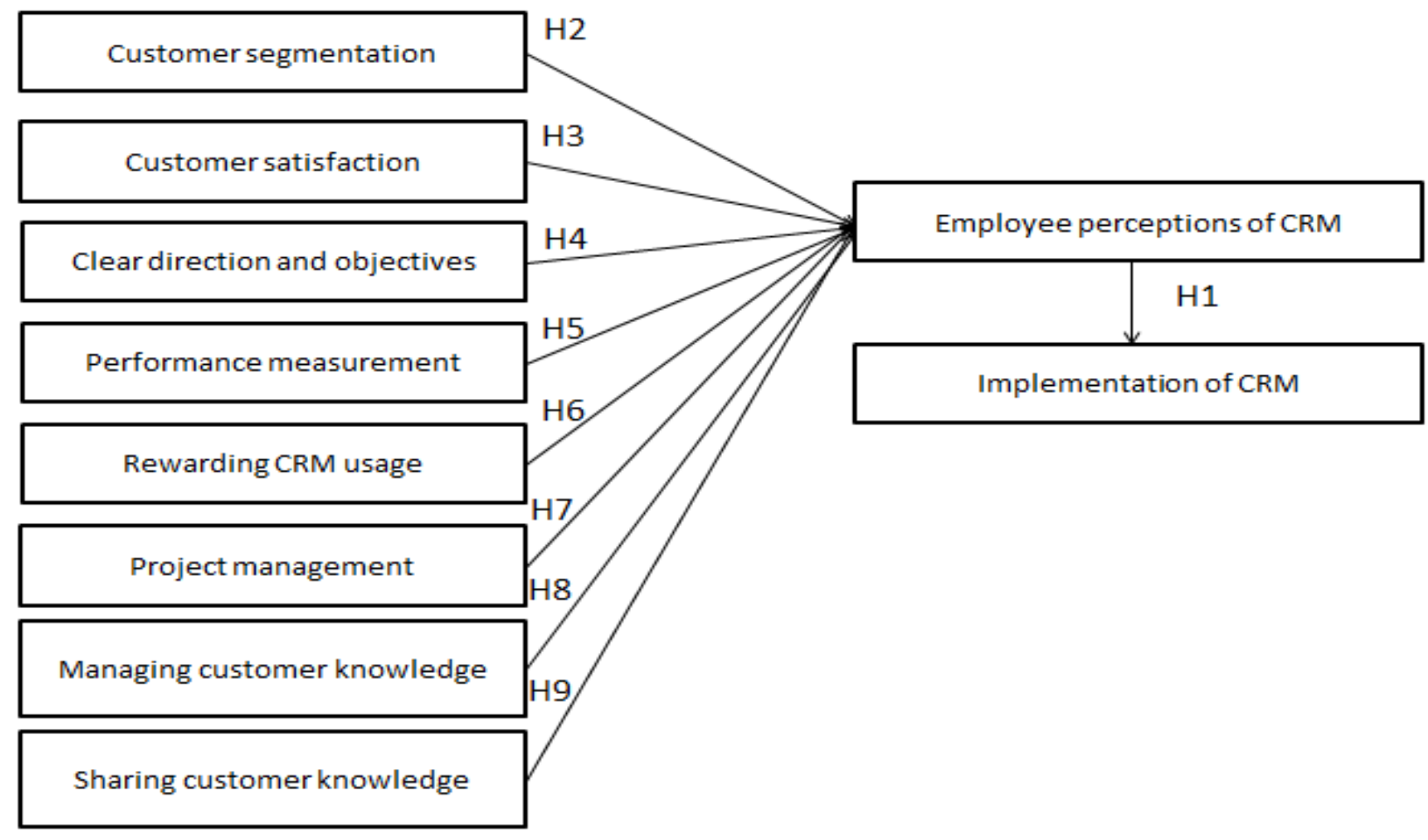

\section{Methodology}

This research started with a preliminary qualitative study, derived from in-depth interviews, to investigate the subjective perceptions and experiences of a variety of employees, marketing managers, and CIOs working with CRM. This phase also served to contextualise an embedded conceptual framework for the study, as informed by the literature pertinent to CRM conditions in Jordan, a developing economy.

A combination of a literature review alongside in-depth interviews was used to identify measurement scales for variables in this study. Several existing scales across varying disciplines were consulted. The two stages of CRM adoption were measured using scale items of Ko et al. (2008). Customer segmentation was measured using elements developed by Reinartz, Krafft, and Hoyer (2004). Customer satisfaction orientation was measured in accordance with Rapp, Trainor, 
and Agnihotri (2010). Strategic constructs (i.e. clear direction and objectives and performance measurement systems) were measured using a modification of Meadows and Dibb's (2008) scales. The scale items measuring the internal marketing and rewards construct was adapted from Plakoyiannaki's (2005) study. The project management construct was measured using elements of managing changes in the CRM projects scale, developed by Richards and Jones (2008). KM capabilities were measured using measures developed by Croteau et al. (2003).

All measurement items were piloted with participants employed at a hotel in Jordan. The data were collected via self-administered questionnaires distributed to practitioners of ten organisations across four sectors in Jordan: Hospitality, Banking, Telecommunications and Automotive Services (see Appendix I). In investigating CRM adoption across a spread of industries, it was anticipated that the research data from this study would yield a rich and diverse picture of different kinds of potential challenge to CRM adoption. 400 questionnaires were distributed and 322 were returned giving a response rate of $80 \%$. After screening and reviewing the 322 questionnaires, 21 responses were excluded from the study due to a large number of missing values. This left a total number of 301 fully completed responses that were valid for our analysis, for a response rate of $75 \%$. This response rate is on a par with previous social science studies which deem the quality of data acceptable.

\section{Findings}

\subsection{Exploratory factor analysis}

Sin, Tse, and Yim (2005) argued that the measurement scales of CRM are still not sufficiently specific to allow for valid and reliable measurement. As CRM constructs and measure items are, 
to an extent, discipline-derived, exploratory factor analysis (EFA) was used as an initial step to find out whether the underlying factors of the items were those suggested in the conceptual model and whether new items in the survey were grouped to the same extent as proposed. A KMO statistic of .92 indicated that factor analysis was an appropriate technique for reducing and summarising the scale items in this study (Tabachnick and Fiddle 2001). EFA using varimax rotation was performed as a data summarisation technique to ascertain the underlying structure of the data. Using the 0.5 factor loading criterion, altogether 7 items with smaller or crossloadings were eliminated from an initial pool of 37 items, resulting in 30 scale items to measure 8 factors affecting CRM adoption. Cumulatively, the 8 factors explained $67 \%$ of the variance of the quantitative data, which was deemed sufficient to represent the data.

\subsection{Measurement model}

The structural equation modelling (SEM) approach was employed using the two-step modelbuilding recommended by Anderson and Gerbing (1988): assessment of the measurement model and assessment of the structural model. Confirmatory factor analysis using AMOS 22 provided evidence of the measurement model validity based on the goodness-of-fit measure and quantitative measures of constructs reliability and validity.

After examining the goodness-of-fit model variables, modification indices and standardised residuals, seven items were deleted from the original pool of measurement items. A total of twenty-three items were used to measure all adoption factors in this study, four items were used to measure employee perceptions, and five items were used to measure CRM implementation (see Appendix II). The best-fitting measurement model and its related scale items were tested and assessed for validity and reliability (Hair et al. 2006). In investigating reliability, items used to measure the constructs in the conceptual model were found to be highly 
reliable with all three measures of the convergent validity test exceeding Anderson and Gerbing's (1988) suggested levels of acceptance (i.e., 0.70 for construct reliability, 0.50 for AVE, and 0.70 for construct reliability), as shown in Table 2.

Table 2. Summary of measurement model - Convergent validity

\begin{tabular}{lcccc}
\hline Factor & $\begin{array}{c}\text { Number of } \\
\text { variables }\end{array}$ & AVE & $\begin{array}{c}\text { Composite } \\
\text { reliability }\end{array}$ & $\begin{array}{c}\text { Cronbach's } \\
\text { Alpha }\end{array}$ \\
\hline Segmentation (SEGM) & 2 & .63 & .75 & .75 \\
Customer satisfaction (CS) & 3 & .55 & .77 & .77 \\
Clear direction and objectives (CLRD) & 3 & .68 & .86 & .86 \\
Performance management system (PMS) & 3 & .53 & .77 & .76 \\
Rewarding CRM usage (RCRM) & 3 & .68 & .80 & .80 \\
Project management (PM) & 3 & .51 & .76 & .75 \\
Customer knowledge management (CKM) & 3 & .62 & .83 & .83 \\
Customer knowledge sharing (CKS) & 3 & .62 & .83 & .82 \\
Employee perceptions of CRM (PER) & 4 & .55 & .83 & .83 \\
Implementation of CRM (IMP) & 5 & .55 & .77 & .77 \\
\hline
\end{tabular}

As depicted in Table 3, the AVE from each construct was greater than the square of intercorrelations. Therefore, the discriminant validity between factors in the measurement model is present and demonstrated.

Table 3. Discriminant Validity Results

\begin{tabular}{lcccccccccc}
\hline & SEGM & CS & CLRD & PMS & RCRM & PM & CKM & CKS & PER & IMP \\
\hline AVE & .63 & .55 & .68 & .53 & .68 & .51 & .62 & .62 & .55 & .55 \\
SEGM & 1 & & & & & & & & & \\
CS & .26 & 1 & & & & & & & & \\
CLRD & .19 & .33 & 1 & & & & & & &
\end{tabular}




\begin{tabular}{|c|c|c|c|c|c|c|c|c|c|c|}
\hline PMS & .20 & .24 & .45 & 1 & & & & & & \\
\hline RCRM & .09 & .09 & .19 & .20 & 1 & & & & & \\
\hline PM & .28 & .29 & .30 & .25 & .26 & 1 & & & & \\
\hline CKM & .16 & .33 & .34 & .28 & .18 & .45 & 1 & & & \\
\hline CKS & .21 & .20 & .27 & .20 & .10 & .28 & .23 & 1 & & \\
\hline PER & .13 & .37 & .43 & .40 & .16 & .22 & .36 & .20 & 1 & \\
\hline IMP & .16 & .26 & .36 & .28 & .24 & .28 & .22 & .16 & .28 & 1 \\
\hline
\end{tabular}

Following an acceptable fit of the measurement model $\left(\chi^{2}=1397\right.$, AGFI $=0.79$, CFI $=0.91$, RMSEA $=0.04)$, the structural model was then tested and a good-model-fit was established; $\chi^{2}=$ $1380, \mathrm{AGFI}=0.81, \mathrm{CFI}=0.90, \mathrm{RMSEA}=0.04$.

\subsection{Structural effects}

In order to achieve a rigorous result when testing the nine directional hypotheses in Table 4, a rigid level of significance within one-tailed testing was used ( $\mathrm{p}<0.05)$. According to Cho and Abe (2010), a two-tailed test conducts a more conservative rigorous test, but researchers should recognise that substituting two-tailed tests for one-tailed tests results in a lack of logical consistency and may lead to inaccurate conclusions. Hence, the research hypotheses for this study are directional, and one-tailed significance levels are reported. In order to achieve rigorous test results when testing the directional hypotheses, a rigid level of significance within one-tailed testing is used $(\mathrm{p}<.05)$. The AMOS output provides the two-tailed $\mathrm{p}$ value, but it is enough to halve this value to calculate the one-tailed p-value. The one-tailed testing suggests that path values are statistically significant when the significance level (p-value) is less than .05 and the t- 
value (critical ratio) is greater than 1.65 or smaller than -1.65 (Bryne 2001)

Table 4. Total effects

\begin{tabular}{llccccc}
\hline $\begin{array}{l}\text { Hypo } \\
\text {-thesis } \\
\text { number }\end{array}$ & \multicolumn{1}{c}{ Relationship } & $\begin{array}{c}\text { Path } \\
\text { estimate }\end{array}$ & $\begin{array}{c}\text { Standard } \\
\text { error }\end{array}$ & t-value & p-value & Result \\
\hline $\mathrm{H}_{1}$ & Perception $\rightarrow$ Implementation & .22 & .11 & 1.86 & $\mathbf{. 0 3 *}$ & Supported \\
$\mathrm{H}_{2}$ & Segmentation $\rightarrow$ Perception & .25 & .09 & 2.83 & $\mathbf{. 0 0 *}$ & Supported \\
$\mathrm{H}_{3}$ & Customer satisfaction $\rightarrow$ Perception & -.03 & .06 & -.51 & .30 & Rejected \\
$\mathrm{H}_{4}$ & Clear objectives $\rightarrow$ Perception & .19 & .09 & 2.10 & $\mathbf{. 0 1 *}$ & Supported \\
$\mathrm{H}_{5}$ & Performance management $\rightarrow$ Perception & .19 & .07 & 2.50 & $\mathbf{. 0 0 *}$ & Supported \\
$\mathrm{H}_{6}$ & Rewarding CRM usage $\rightarrow$ Perception & .04 & .04 & .86 & .19 & Rejected \\
$\mathrm{H}_{7}$ & Project management $\rightarrow$ Perception & -.08 & .10 &.- .77 & .22 & Rejected \\
$\mathrm{H}_{8}$ & Customer knowledge management $\rightarrow$ Perception & .20 & .09 & 2.18 & $\mathbf{. 0 1 *}$ & Supported \\
$\mathrm{H}_{9}$ & Customer knowledge sharing $\rightarrow$ Perception & .07 & .07 & .97 & .16 & Rejected \\
& Clear objectives $\rightarrow$ Implementation & .36 & .11 & 3.10 & $\mathbf{. 0 0 *}$ &
\end{tabular}

Model Fit Statistics

$\chi^{2}-1380$

Degree of freedom (Df) 811

$\chi^{2} / \mathrm{Df} \quad 1.70$

AGFI $\quad .81$

RSMEA $\quad .40$

$\begin{array}{ll}\text { CFI } & .90\end{array}$

Variance Explained $\left(R^{2}\right)$

Perception $\quad .62$

$\begin{array}{ll}\text { Implementation } & .50\end{array}$ 
Overall, the findings of this study confirm that six factors affect the CRM adoption process. Five out of the nine research hypotheses were supported; $\mathrm{H}_{1}, \mathrm{H}_{2}, \mathrm{H}_{4}, \mathrm{H}_{5}$ and $\mathrm{H}_{8}$. The t-values (1.86 and 2.83) exceeded the recommended threshold of the one-tailed test at 1.65 with significant levels less than 0.05 .

\section{Discussion}

\subsection{Effects of employee perceptions on organisation's implementation of CRM}

We predicted in $\mathrm{H}_{1}$ that employee perception of CRM should have a positive relationship with organisations' implementation of CRM. As shown in Table 4, the results of this study strongly support this proposition $(\beta=0.22, \mathrm{t}=1.86, \mathrm{p}<0.05)$. Furthermore, we suggest that employees' perception is the main determinant of CRM implementation as it mediates the impact of four organisational settings on CRM widespread implementation across an organisation. These findings are consistent with prior research which concludes that perceptions of individuals in organisation tend to mediate the impact of external factors on the implementation of CRM (Plakoyiannaki 2005).

Although not hypothesised, our results showed that clear direction, rewarding usage, and controlling a project's changes have significant effects on the implementation of CRM within organisations. This shows that factors affecting CRM adoption can have a different effect at different points in the adoption process. Although this claim is supported by many IT researchers investigating innovation adoption (e.g. Damanpour and Schneider 2006), prior studies in the business discipline do not seem to recognise that factors affecting CRM adoption vary at different stages. 
First, our results suggest that having clear direction and objectives of CRM influences not only employee perceptions of CRM but also its implementation across an organisation. This suggests that the more managers communicate clear objectives of CRM with their employees, the more motivated employees are to accept and use CRM across organisations. The important role of having clear direction in the Arab world might be explained by the observation of Elbanna, Ali, and Dayan (2011) stressing that employees there often agree with their managers and leaders. Similarly, many researchers confirm the important role of formal planning and respect for seniority in the Arab world (Al-Shammari and Hussein 2007; Elbanna, Ali, and Dayan 2011).

Second, our results suggest that rewarding CRM usage encouraged organisations to embrace CRM technologies, even when employees were not yet comfortable with these. In this event, it can be argued that employees are moved rather than motivated. This is strongly connected with Herzberg's argument (1987 as cited in Bassett-Jones and Lloyd 2005) that it is 'because of movement' - in this context, movement towards the implementation of CRM - that 'traditional individualised incentives' seem appropriate for rewarding employees. Such movement and rewards are no guarantee of employees' motivation to change, though.

Third, our findings indicate that managing changes in CRM projects does not influence the perception of CRM amongst employees, but does influence its implementation. These seemingly inconsistent findings can be explained when a closer look is taken at the differences between the Western and Arabic practices of project management. A comparative study by RessCaldwell and Pinnington (2013) on the difference between British and Arab organisations indicates that the two cultures have different interpretations and expectations regarding project management practices. In the same vein, other studies indicate that culture influences a wide 
range of project management practices including: project management planning, communicating, risk assessment, and leadership (De Bony 2010; Zwikael and Ahn 2011; Rees-Caldwell and Pinnington 2013).

\subsection{Factors influencing employee perceptions of CRM}

Our results support $\mathrm{H}_{2}$, which suggests that an organisation's emphasis on segmentation analysis will have a positive effect on employee perceptions of $C R M(B=0.25, t=2.83, p<0.05)$. More precisely, the effective use of segmentation analysis to evaluate customers' lifetime value is found to be a critical part in helping staff to relate more easily to CRM values. This is consistent with previous studies that have often tied CRM with segmentation analysis (e.g. Reinartz, Krafft, and Hoyer 2004; Bailey et al. 2009; Kim et al. 2012). Thus, our study suggests that employees understand and realise the benefits associated with CRM when their organisations focus on generating insight into individual customer needs as an essential business strategy and philosophy.

The results also support $\mathrm{H}_{4}(B=0.19, \mathrm{t}=2.10, \mathrm{p}<0.05)$ and $\mathrm{H}_{5}(\beta=0.19, \mathrm{t}=2.50, \mathrm{p}<0.05)$, which suggest that having clear direction and objectives and appropriate CRM performance measurement mechanisms in an organisation positively affects employee perceptions of CRM. This finding reinforces Brown and Vessey's (2003), Gurau, Ranchhod, and Hackney (2003) and Steel, Dubelaar, and Ewing (2013) suggestion that having clear CRM objectives and providing performance measures enable strong support among senior management, in order to create an organisational environment that is conducive to effective implementation of CRM strategy across the organisation. Hence, we suggest that every organisation needs to establish and agree on its CRM objectives and on what exactly will bring value to their business. In other words, it should be clear in the organisation how CRM strategy supports the overall business strategy, by 
building and developing customer relationships for a sustained competitive advantage. A possible benefit from such a strategic approach towards CRM could be the opportunity to assess and diagnose its progress, which would result in tailoring CRM measures that are valuable and relevant to each group of stakeholders' responsibilities. This is especially true because having clear objectives and performance measures of CRM has a positive relationship with employee evaluation of the potential benefits of CRM in an organisation, since these provide accountability for strategies geared toward customer focus.

In accordance with previous studies (Rigby, Reichheld, and Schefter 2002; Sin, Tse, and Yim 2005; Khodakarami and Chan 2014), our findings support $\mathrm{H}_{8}(\beta=0.20, \mathrm{t}=2.18, \mathrm{p}<0.05)$, which indicates that organisational capability to manage customer knowledge positively affects employee perceptions of CRM. This indicates that organisations that use knowledge management are reported to appreciate CRM offerings and hence to be more innovative. These finding are highly compatible with observations made by Rigby, Reichheld, and Schefter (2002) and Rollins and Halinen (2005) which stress that managing customer data is fundamental in justifying CRM adoption. In addition, Daghfous (2007) suggests that CRM requires knowledge management tools, such as business intelligence tools, to support its adoption. Although we predicted that customer satisfaction $\left(\mathrm{H}_{3}\right)$, rewarding CRM usage $\left(\mathrm{H}_{6}\right)$, managing changes in CRM projects $\left(\mathrm{H}_{7}\right)$ and sharing customer knowledge $\left(\mathrm{H}_{9}\right)$ should positively influence employee perceptions of CRM, the findings of this study do not support these hypotheses. These results might be explained by the economic development, market conditions, and cultural values of the Arab world; these differences impact a variety of managerial practices and customer orientation activities, including metrics to track customer satisfaction, buyer-seller interactions, and the ways customer relationships start and develop (Ramesham et al. 2006; ALHussan, AL- 
Husan, and Chavi 2014). Moreover, the typical hierarchal management structures alongside the weak institutional structures in the Arab world made it difficult for organisations to develop a viable customer-centric orientation. In the Middle East, 'wasta' is considered as an informal institution which reflects the tribal mentality in this region and enables people and organisations to achieve their goals through personal networks of family and friends (ALHussan, AL-Husan, and Chavi 2014; Barnes et al. 2015; Smith et al. 2012). This informal institution is very similar to 'guanxi' in China (Smith et al. 2012).

\section{Conclusion, Limitations and Future Research}

As they engage with CRM, organisations in the Arab world are finding themselves faced with challenges specific to them. Hence, understanding CRM adoption there requires approaches that are flexible enough to consider a wide range of factors. While much is known about organisational adoption of CRM in the Western and Asia/Pacific countries, comparatively little is known about their equivalent in the Arab world, given most CRM studies conducted there suffer from conceptual and methodological flaws. The marketing, management and IT literatures include a great number of theoretical models that describe CRM adoption factors (Boulding et al. 2005; Payne and Frow 2006; Plakoyiannaki 2005; Reinartz, Krafft, and Hoyer 2004; Rigby, Reichheld, and Schefter 2002; Ryals and Payne 2001; Thakur et al. 2006, Tseng, 2016). Determinants of CRM success are well summarised in the model by Payne and Frow (2006). Their model highlights various key elements in the CRM strategy and implementation model. However, the particular aspects of these elements are not identified. Hence, the current research builds on the work of Payne and Frow (2006), Ko et al. (2008) and others, such as Meadows and Dibb (2012), Padilla-Meléndez and Garrido-Moreno (2014) and Navimipour and Soltani (2016), to comprehensively provide a systematic empirical explanation of CRM adoption within 
organisations in the Arab world.

In this research, a qualitative study was conducted first to evaluate the relevance of factors identified from the literature as well as the application of these factors for organisations across varied sectors in Jordan. Subsequently, a quantitative study was employed to examine dimensionality and the relative importance of each factor in the research model. The quantitative study was completed by 322 practitioners from ten organisations across four service sectors (banking and finance, telecommunication, hospitality and automotive) in Jordan. The data was then analysed using exploratory factor analysis and structural equation modelling. The SEM results showed that our model sufficiently predicted drivers of CRM adoption in Jordan. Despite some unexpected results, the explanatory power of employee perceptions of CRM was excellent (60\%). Similarly, the explanatory power of the model in explaining CRM implementation was found to be strong (48\%), which suggests that the results provide a plausible answer to the question as to what factors aid the adoption of CRM in the Arab world.

The findings of this study are useful for practitioners learning how CRM challenges can be addressed. It is evident that in the Arab world, CRM introduces a new way of working with customers to establish a mutual value. Hence, so much of this study reaches beyond the adoption of CRM practices. There are lessons for organisations in developing countries seeking to launch many projects and adopt many new practices. First, organisations that aspire to pursue creative ideas and approaches should seek to encourage creativity by developing a working environment that is conducive to innovation, change, and continuous learning orientation. Second, while the capabilities of an organisation to react quickly and support new solutions must start at the individual level within the organisation, this study proves that these capabilities are impacted by a variety of organisational variables, such as strategy, customer orientation, and knowledge 
management capabilities. These variables are proved to be useful in explaining how organisations influence the attitudes and behaviour of organisational members, why some organisations are more innovative and more willing to adopt new methods, and why some organisations are more successful than others. Third, there will be on going knock-on ramifications required, particularly in changing employee attitudes, shaping the culture of an organisation, and providing top management support and commitment. These ramifications should be raised if the implementation of new desired practices is to occur. Failure to address these matters will leave organisations unable or unprepared to adopt innovative approaches/strategies.

CRM is a global concept implemented by many organisations around the world. Previous research has mostly investigated organisational adoption of CRM in the US, the Europe and Asia pacific and there is little research in developing countries. This paper makes an important theoretical contribution to our understanding of CRM adoption in Jordan as part of the Arab world. However, there is still a need to investigate CRM adoption in different developing countries/contexts. Hence, this study cautions against recommending a universal framework for CRM adoption in the developing world. With more replicative and creative research, it is expected that a more comprehensive conceptual framework of CRM adoption can be offered in the near future. Another limitation of the study is that this research did not consider the influence of CRM adoption on business performance; whether this is part of financial performance, improved relationships and higher customer satisfaction or brand loyalty. Hence, exploring the complexities of the relationship between CRM adoption and business performance is one of the areas for further research. Third, research suggests that social media technologies, due to their personal, interactive, and relational nature have great potential for CRM (Harrigan et al. 2011; 
Nair 2011). These technologies are different to previous software package technologies used in CRM (Harrigan et al. 2011). Social media enable businesses to interact with and gather customer information. Hence, further research should shed light on the area of social CRM and its potential to influence CRM adoption process. 
Acknowledgments: The authors would like to thank Yuksel Ekinci (Brunel University) and Ana Domingos Canhoto (Brunel University) for their continuous support during the development of this research. 
Appendix I. Organisations' characteristics

\begin{tabular}{|c|c|c|}
\hline Variable & Number of respondents & Percent (\%) \\
\hline \multicolumn{3}{|c|}{ Industry } \\
\hline Banking and finance & 99 & 32.8 \\
\hline Telecommunication & 83 & 27.4 \\
\hline Hotel & 81 & 26.9 \\
\hline Automotive & 38 & 12.6 \\
\hline \multicolumn{3}{|c|}{ Number of employees } \\
\hline 25 or less & 7 & 2.3 \\
\hline $26-50$ & 8 & 2.7 \\
\hline $51-100$ & 12 & 4.0 \\
\hline $101-155$ & 3 & 1.0 \\
\hline $151-200$ & 13 & 4.3 \\
\hline More than 201 & 258 & 85.7 \\
\hline \multicolumn{3}{|c|}{ Turnover } \\
\hline Less than $25 \mathrm{~m}$ & 86 & 28.6 \\
\hline $26 \mathrm{~m}-50 \mathrm{~m}$ & 52 & 17.3 \\
\hline $51 \mathrm{~m}-100 \mathrm{~m}$ & 33 & 11.0 \\
\hline $101 \mathrm{~m}-155 \mathrm{~m}$ & 6 & 2.0 \\
\hline $151 \mathrm{~m}-200 \mathrm{~m}$ & 19 & 6.3 \\
\hline More than $201 \mathrm{~m}$ & 86 & 28.6 \\
\hline \multicolumn{3}{|c|}{ eship type } \\
\hline
\end{tabular}




\begin{tabular}{|c|c|c|}
\hline Variable & Number of respondents & Percent (\%) \\
\hline Sole proprietorship & 20 & 6.6 \\
\hline Partnership & 128 & 42.5 \\
\hline Joint venture & 117 & 38.9 \\
\hline Subsidiary & 10 & 3.3 \\
\hline Associate company & 2 & .7 \\
\hline Corporation & 6 & 2.0 \\
\hline Other & 18 & 6.0 \\
\hline \multicolumn{3}{|c|}{ Operation of the organisation } \\
\hline Regional & 108 & 35.9 \\
\hline International & 193 & 64.1 \\
\hline \multicolumn{3}{|c|}{ Speed of response to change } \\
\hline Slow & 11 & 3.7 \\
\hline Fair & 120 & 39.9 \\
\hline Fast & 170 & 56.5 \\
\hline
\end{tabular}




\section{Appendix II. Factors and scale items}

\begin{tabular}{|c|c|}
\hline Factor & Variables \\
\hline \multirow{3}{*}{$\begin{array}{l}\text { Clear direction } \\
\text { and objectives }\end{array}$} & Clear business goals related to customer acquisition, development, and retention. \\
\hline & The majority of the employees are aware of the organisation's vision. \\
\hline & Approaching customers as an important part of the organisational vision. \\
\hline \multirow{3}{*}{$\begin{array}{l}\text { Performance } \\
\text { management } \\
\text { system }\end{array}$} & There is a set of clear priorities for CRM projects. \\
\hline & These CRM projects are consistent with the organisation's vision and statements. \\
\hline & Regularly measuring the effectiveness and the success of CRM activities. \\
\hline \multirow[t]{2}{*}{ Segmentation } & Using customer information to segment markets. \\
\hline & Segmenting customers based on their lifetime. \\
\hline \multirow{3}{*}{$\begin{array}{l}\text { Customer } \\
\text { satisfaction }\end{array}$} & Organisation strategy is driven by customer satisfaction. \\
\hline & Frequently and systematically measuring customer satisfaction. \\
\hline & Responding quickly to negative customer satisfaction wherever it may occur. \\
\hline \multirow{3}{*}{$\begin{array}{l}\text { Rewarding } \\
\text { CRM usage }\end{array}$} & Organisation policy which rewards the use of CRM. \\
\hline & Rewarding employees who use CRM to provide excellent customer service. \\
\hline & The reward systems encourage employees to work with CRM system. \\
\hline \multirow[t]{3}{*}{$\begin{array}{l}\text { Project } \\
\text { management }\end{array}$} & $\begin{array}{l}\text { Giving users' ideas due attention in the CRM planning and implementation } \\
\text { process. }\end{array}$ \\
\hline & $\begin{array}{l}\text { Meeting changes in CRM requirements by users or due to business environment } \\
\text { change. }\end{array}$ \\
\hline & The IT function has the ability to adjust CRM project plans on an ad hoc basis. \\
\hline
\end{tabular}




\begin{tabular}{|c|c|}
\hline \multirow{3}{*}{$\begin{array}{l}\text { Customer } \\
\text { knowledge } \\
\text { management }\end{array}$} & $\begin{array}{l}\text { Providing fast customer response because of integrated customer knowledge } \\
\text { across several functional areas. }\end{array}$ \\
\hline & Providing fast decision-making due to customer knowledge availability. \\
\hline & Providing authentic customer information for quick and accurate interaction. \\
\hline \multirow{3}{*}{$\begin{array}{l}\text { Sharing } \\
\text { customer } \\
\text { knowledge }\end{array}$} & Individual customer information is available at every point of contact. \\
\hline & Information on customers is disseminated throughout the organisation. \\
\hline & Customer information is redirected to the right people. \\
\hline \multirow{4}{*}{$\begin{array}{l}\text { Employee } \\
\text { perceptions of } \\
\text { CRM }\end{array}$} & Increase customer satisfaction. \\
\hline & Increase customer retention rate. \\
\hline & Increase revenue and profitability. \\
\hline & Enhance customer relationships. \\
\hline \multirow{5}{*}{$\begin{array}{l}\text { Implementation } \\
\text { of CRM }\end{array}$} & Offering customer loyalty programme \\
\hline & Managing customer loyalty \\
\hline & Developing member-only site in your organisation's website \\
\hline & Categorising/segmenting customers based on spending (lifetime value) \\
\hline & Providing products and services in one place \\
\hline
\end{tabular}




\section{References}

ALHussan, F. B., F. B. AL-Husan, and C.Y. Chavi. 2014. "Environmental Factors Influencing the Management of Key Accounts in an Arab Middle Eastern Context.” Industrial Marketing Management 43 (4): 592-602.

Al-Shammari, H., and A. R. T. Hussein. 2007. "Strategic Planning-Firm Performance Linkage: Empirical Investigation from an Emergent Market Perspective." Advanced in Competitiveness Research 15 (1\&2): 15-26.

Anderson, J. C., and D. W. Gerbing. 1988. "Structural Equation Modelling in Practice: A Review and Recommended Two-step Approach.” Psychological Bulletin 103 (3): 411423.

Bailey, C., P. R. Baines, H. Wilson, and M. Clark. 2009. "Segmentation and Customer Insight in Contemporary Services Marketing Practice: Why Grouping Customers is No Longer Enough.” Journal of Marketing Management 25 (3-4): 227-252.

Ballantyne, D. 2003. “A Relationship Mediated Theory of Internal Marketing.” European Journal of Marketing 37 (12): 42-1260.

Barnes, B. R., L. C. Leonidou, N. Y. Siu, and C. N. Leonidou. 2015. “Interpersonal Factors as Drivers of Quality and Performance in Western-Hong Kong Interorganizational Business Relationships.” Journal of International Marketing 23 (1): 23-49.

Bassett-Jones, N., and G. Lloyd. 2005. “Does Herzberg's Motivation Theory Have Staying Power.” Journal of Management Development 24 (10): 929-943.

Blattberg, R., R. Malthouse, and S. Neslin. 2009. “Customer Lifetime Value: Empirical Generalizations and Some Conceptual Questions.” Journal of Interactive Marketing 23 (2): $157-168$. 
Boulding, W., R. Staelin, M. Ehret, and W. J. Johnston. 2005. “A CRM Roadmap: What We Know, Potential Pitfalls, and Where to Go.” Journal of Marketing 69 (4): 155-167.

Brown, C. V., and I. Vessey. 2003. "Managing the Next Wave of Enterprise Systems:

Leveraging Lessons from ERP.” MIS Quarterly_Executive 2 (1): 65-77.

Cascio, R., B. Mariadoss, and N. Mouri. 2010. “The Impact of Management Commitment Alignment on Salespersons' Adoption of Sales Force Automation Technologies: An Empirical Investigation.” Industrial Marketing Management 39 (7): 1088-1096.

Chen, I.J. and Popovich, K., 2003. Understanding customer relationship management (CRM) People, process and technology. Business process management journal, 9(5): 672-688.

Clark, M., and S. Baker. 2004. Business Success Through Service Excellence. Oxford: Elsevier Butterworth-Heinemann.

Damanpour, F., and M. Schneider. 2006. "Phases of the Adoption of Innovation in Organizations: Effects of Environment Organization and Top Managers.” British Journal of Management 17 (3): 215-236.

Davis, F. D. 1989. "Perceived Usefulness, Perceived Ease of Use, and User Acceptance of Information Technology." MIS Quarterly 13 (3): 319-340.

Day, G. S. 1999. The Market Driven Organization: Understanding, Attracting, and Keeping Valuable Customers. The Free Press.

Elbanna, S., A. J. Ali, and M. Dayan. 2011. "Conflict in Strategic Decision Making: Do the Setting and Environment Matter?” International Journal of Conflict Management 22 (3): $278-299$.

Enz, M., and D. Lambert. 2012. "Using Cross-functional, Cross-firm Teams to Co-create Value: The Role of Financial Measures.” Industrial Marketing Management 41, 495-507. 
European Union. “Countries and Regions: Jordan.” Last modified 22 February 2017. http://ec.europa.eu/trade/creating-opportunities/bilateral-relations/countries/jordan/.

Fishbein, M. and Ajzen, I., 1975. Attitude, Intention and Behavior. In An Introduction to Theory and Research. Addison-Western, Boston.

Forrester. "Map the way to your CRM business outcomes." Last modified 30 August 2016. https://www.forrester.com/Map+The+Way+To+Your+CRM+Business+Outcomes/fulltex t/-/E-RES90061.

Foss, B., Stone, M. and Ekinci, Y., 2008. What makes for CRM system success-Or failure?. Journal of Database Marketing \& Customer Strategy Management, 15(2), 6878.

Garrido-Moreno, A., and A. Padilla-Melendez. 2011. "Analyzing the Impact of Knowledge Management on CRM Success: The Mediating Effects of Organizational Factors." International Journal of Information Management 31 (5): 437-444.

Gartner. "Market Share Analysis: Customer Relationship Management Software, Worldwide, 2015” Published 12 May 2016. https://www.gartner.com/doc/3315925/market-shareanalysis-customer-relationship.

Gartner. Published 09 May 2016. "The Gartner CRM Vendor Guide, 2016”. https://www.gartner.com/doc/3311217/gartner-crm-vendor-guide-

Gebert, H., M. Geib, L. Kolbe, and W. Brenner. 2003. “Knowledge-enabled Customer Relationship Management: Integrating Customer Relationship Management and KM Concepts." Journal of Management 7 (5): 107-123.

Gefen, D., and C. M. Ridings. 2002. "Implementation Team Responsiveness and User Evaluation of Customer Relationship Management: A Quasi-experimental Design Study of Social Exchange Theory.” Journal of Management Information Systems 19 (1): 47-69. 
Gibbert, M., M. Leibold, and G. Probst. 2002. "Five Styles of Customer Knowledge Management, and How Smart Companies Use Them to Create Value.” European Management Journal 20 (5): 459-469.

Grönroos, C. 2000. Service Management and Marketing: A Customer Relationship Management Approach. $2^{\text {nd }}$ ed. Chichester, England: John Wiley and Sons.

Gurau, C., A. Ranchhod, and R. Hackney. 2003. "Customer-centric Strategic Planning: Integrating CRM in Online Business Systems." Information Technology and Management 4 (2/3): 199-214.

Hair, J., W.C. Black, B. Babin, R. E. Anderson, and R. L. Tatham. 2006. Multivariate Data Analysis. $6^{\text {th }}$ ed. Englewood Cliffs: Prentice Hall.

Horn, D., R. Feinberg, and G. Salvendy. 2005. "Determinant Elements of Customer Relationship Management in e-Business.” Behaviour \& Information Technology 24 (2): 101-109.

Hsu, M. H., and C. M. Chiu. 2004. "Predicting Electronic Service Continuance with a Decomposed Theory of Planned Behaviour.” Behaviour \& Information Technology 23 (5): $359-374$.

Khodakarami, F., and Y. E. Chan. 2014. "Exploring the Role of Customer Relationship Management (CRM) Systems in Customer Knowledge Creation.” Information and Management 51 (1): 27-42.

Kim, H., and Y. Kim. 2009. “A CRM Performance Measurement Framework: Its Development Process and Application.” Industrial Marketing Management 38 (4): 477-489.

Kim, M., J. Park, A. J. Dubinsky, and S. Chaiy. 2012. "Frequency of CRM Implementation Activities: A Customer-centric View.” Journal of Services Marketing 26 (2), 83-93. 
Ko, E., S. H. Kim, M. Kim, and J. Woo. 2008. “Organisational Characteristics and the CRM Adoption Process." Journal of Business Research 61, 65-74.

Kotler, P., Keller, K.L., Brady, M., Goodman, M. and Hansen, T., 2016. Marketing Management $3^{\text {rd }}$ edition. Pearson.

Krasnikov, A., Jayachandran, S. and Kumar, V., 2009. The impact of customer relationship management implementation on cost and profit efficiencies: evidence from the US commercial banking industry. Journal of marketing, 73(6): 61-76.

Kumar, V., Sunder, S. and Ramaseshan, B., 2011. Analyzing the diffusion of global customer relationship management: A cross-regional modeling framework. Journal of International Marketing, 19(1):.23-39.

Kutner, S. and Cripps, J., 1997. Managing the customer portfolio of healthcare enterprises. Data driven marketing. In The Healthcare Forum Journal 40 (5): 52.

Lee-Kelley, L., D. Gilbert, and R. Mannicom. 2003. "How e-CRM Can Enhance Customer Loyalty.” Marketing Intelligence and Planning 21 (4): 239-248.

Lin, R.J., Chen, R.H. and Kuan-Shun Chiu, K., 2010. "Customer relationship management and innovation capability: an empirical study". Industrial Management \& Data Systems, 110(1): 111-133.

Maklan, M., J. Peppard, and P. Klaus. 2015. "Show Me the Money: Improving Our Understanding of How Organizations Generate Return from Technology-led Marketing Change." European Journal of Marketing 49 (3/4): 561-595.

Maklan, S. and Knox, S., 2009. Dynamic capabilities: the missing link in CRM investments. European Journal of Marketing, 43(11/12), 1392-1410

Man, C. W., W. Y. W. Kong, W. H. E. Yui, and P. F. J.Tam. 2006. “A study of CRM Implementation in Financial Industry." International Conference on e-Learning, eBusiness, Enterprise Information Systems, e-Government, and Outsourcing, 237-244.

Massey, A., M. Montoya, and K. Holcom. 2001. "Re-engineering the Customer Relationship: Leveraging Knowledge Assets at IBM.” Decision Support Systems 32 (2): 155-170. 
Meadows, M., and S. Dibb. 2012. "Progress in Customer Relationship Management Adoption: A Cross-sector Study.” Journal of Strategic Marketing 20 (4): 323-344.

Navimipour, N.J. and Soltani, Z. (2016). The impact of cost, technology acceptance and employees' satisfaction on the effectiveness of the electronic customer relationship management systems. Computers in Human Behavior_55, 1052-1066.

Newby, M., T. H. Nguyen, and T. S. Waring. 2014. "Understanding Customer Relationship Management Technology Adoption in Small and Medium-sized Enterprises.” Journal of Enterprise Information Management 27 (5): 541-560.

Ocker, J., and S. Mudambi. 2003. "Assessing the Readiness of Firms for CRM: A Literature Review and Research Model." Proceedings of the 36th Hawaii International Conference on System Sciences.

Osarenkhoe, A., and A. E. Bennani. 2007. “An Exploratory Study of Implementation of Customer Relationship Management and Strategy.” Business Process Management 13 (1): 139-164.

Padilla-Meléndez, A. and Garrido-Moreno, A. (2014). Customer relationship management in hotels: Examining critical success factors. Current Issues in Tourism 17(5), 387-396.

Parvatiyar, A. and Sheth, J.N., 2001. Customer relationship management: Emerging practice, process, and discipline. Journal of Economic and Social research, 3(2), 1-34.

Payne, A. (2006). Handbook of CRM: Achieving Excellence in Customer Management. Amsterdam: Butterworth-Heinemann.

Payne, A., and P. Frow. 2005. “A Strategic Framework for Customer Relationship Management." Journal of Marketing 69 (4): 167-176.

Payne, A., and P. Frow. 2006. "Customer Relationship Management: From Strategy to Implementation.” Journal of Marketing Management 22 (1-2): 135-168. 
Pedron, C.D. and Caldeira, M., 2011. Customer relationship management adoption: using a dynamic capabilities approach. International Journal of Internet Marketing and Advertising, 6(3), pp.265-281.

Plakoyiannaki, E. 2005. "How Do Organizational Members Perceive CRM? Evidence from a UK Service Firm.” Journal of Marketing Management 21 (3-4): 363-392.

Rahimi, R. and Kozak, M. (2017). Impact of Customer Relationship Management on Customer Satisfaction: The Case of a Budget Hotel Chain. Journal of Travel \& Tourism Marketing 34(1), 40-51.

Rahimi, R., and E. Gunlu. 2016. "Implementing Customer Relationship Management (CRM) in Hotel Industry from Organizational Culture Perspective: Case of a Chain Hotel in the UK.” International Journal of Contemporary Hospitality Management 28 (1), 89-112.

Rahimi, R., Gunlu, E. (2016). Implementing Customer Relationship Management (CRM) in hotel industry from organizational culture perspective: Case of a chain hotel in the UK. International_Journal of Contemporary Hospitality Management 28(1), 89-112.

Ramaseshan, B., Bejou, D., Jain, S.C., Mason, C. and Pancras, J., 2006. "Issues and Perspectives in Global Customer Relationship Management”. Journal of Service Research 9(2):195207.

Rapp, A., K. J. Trainor, and R. Agnihotri. 2010. "Performance Implications of Customer-linking Capabilities: Examining the Complementary Role of Customer Orientation and CRM Technology.”Journal of Business Research 63 (11): 1229-1236.

Reimann, M., Schilke, O. and Thomas, J.S., 2010. "Customer relationship management and firm performance: the mediating role of business strategy". Journal of the Academy of Marketing Science, 38(3): 326-346.

Reimer, K., O. J. Rutz, and K. Pauwels. 2014. "How Online Consumer Segments Differ in Longterm Marketing Effectiveness.” Journal of Interactive Marketing 28: 271-284. 
Reinartz, W. J., M. Krafft, and W. D. Hoyer. 2004. "The Customer Relationship Management Process: Its Measurement and Impact on Performance." Journal of Marketing Research 41 (3): 293-305.

Richards, K. A., and E. Jones. 2008. "Customer Relationship Management: Finding Value Drivers." Industrial Marketing Management 37 (2): 120-130.

Rigby, D. K., F. F. Reichheld, and P. Schefter. 2002. “Avoid the Four Perils of CRM.” Harvard Business Review 80 (2): 101-109.

Rogers, E. M. 1983. Diffusion of Innovations. $3^{\text {rd }}$ ed. New York: Free Press.

Roland, R., and P. C. Verhoef. 2005. “Optimizing the Marketing Interventions Mix in Intermediate-term CRM.” Marketing Science 24 (3), 477-489.

Romano, N. C., and J. Fjermestad. 2003. "Electronic Customer Relationship Management: A Research Agenda." Information Technology and Management 4 (2-3): 233-258.

Shum, P., L. Bove, and S. Auh. 2008. “Employees' Affective Commitment to Change: The Key to Successful CRM Implementation.” European Journal of Marketing 42 (1/12): 13461371.

Sin, L. Y. M., A. C. B. Tse, and F. H. K. Yim. 2005. "CRM: Conceptualization and Scale Development.” European Journal of Marketing 39 (11/12): 1264-1290.

Smith, P. B., C. Torres, C. H. Leong, P. Budhwar, M. Achoui, and N. Lebedeva. 2012. "Are Indigenous Approaches to Achieving Influence in Business Organizations Distinctive? A Comparative Study of Guanxi, Wasta, Jeitinho, Svyazi and pulling strings.” The International Journal of Human Resource Management 23 (2): 333-348.

Soltani, Z. and Navimipour, N.J. (2016). Customer relationship management mechanisms: A systematic review of the state of the art literature and recommendations for future research. Computers in Human Behavior 61, 667-688. 
Steel, M., C. Dubelaar, and M. T. Ewing. 2013. Developing Customised CRM Projects: The Role of Industry Norms, Organisational Context and Customer Expectations on CRM Implementation. Industrial Marketing Management 42 (8): 1328-1344.

The World Bank. "Services, etc., value added (\% of GDP).” Accessed 2 March 2017. http://data.worldbank.org/indicator/NV.SRV.TETC.ZS.

Trainor, K. J., A. Rapp, L. Beitelspacher, and N. Schillewaert. 2011. "Integrating Information Technology and Marketing: An Examination of the Drivers and Outcomes of eMarketing capability." Industrial Marketing Management 40 (1): 162-174.

Tukel, O. I., and A. Dixit. 2013. "Application of Customer Lifetime Value Model in Make-toOrder Manufacturing.” Journal of Business and Industrial Marketing 28 (6): 468-474.

Vella, J., and A. Caruana. 2012. "Encouraging CRM Systems Usage: A Study Among Bank Managers.” Management Research Review 35 (2): 121-133.

Wang, Y. and Feng, H., 2012. "Customer relationship management capabilities: Measurement, antecedents and consequences". Management Decision, 50(1):115-129.

Wilson, H., E. Daniel, and M. McDonald. 2002. "Factors for Success in Customer Relationship Management (CRM) Systems.” Journal of Marketing Management 18 (1/2): 193-219.

Winer, R.S., 2001. A framework for customer relationship management. California management review, 43(4), pp.89-105.

Wu, K. L., and K. W. Wu. 2005. “A Hybrid Technology Acceptance Approach for Exploring eCRM Adoption in Organizations.” Behaviour \& Information Technology 24 (4): 303316.

Zahay, D., J. Peltier, A. K. Krishen, and D. E. Schultz. 2014. “Organizational Processes for B2B Services IMC Data Quality.” Journal of Business and Industrial Marketing 29 (1): 6374. 


\section{Figure captions}

Figure 2. Proposed conceptual framework 